\title{
A nondominated sorting ant colony optimization algorithm for complex assembly line balancing problem incorporating incompatible task sets
}

\author{
Uyumsuz iş setlerini içeren karmaşık montaj hattı dengeleme problemi için \\ bastırılmamış sınıflandırmalı karınca koloni optimizasyonu algoritması
}

\author{
Ibrahim KUCUKKOC ${ }^{*}$ iD
}

1Department of Industrial Engineering, Faculty of Engineering, Balikesir University, Balikesir, Turkey. ikucukkoc@balikesir.edu.tr

\begin{abstract}
Two-sided assembly lines are heavily used in automotive industry for producing large-sized products such as buses, trucks and automobiles. Mixed-model lines help manufacturers satisfy customized demands at a reasonable cost with desired quality. This paper addresses to mixedmodel two-sided lines incorporating incompatible task groups and proposes a new method for minimizing two conflicting objectives, namely cycle time and the number of workstations, to maximize line efficiency. While such an approach yields to a so-called type-E problem in the line balancing domain, the proposed nondominated sorting ant colony optimization (NSACO) approach provides a set of solutions dominating others in terms of both objectives (pareto front solutions). The solution which has the highest line efficiency among pareto front solutions is then determined as the best solution. An additional performance criterion is also applied when two different solutions have the same values for both objectives. The solution which has the smoother workload distribution is favoured when both criteria are the same. NSACO is described and a numerical example is provided to exhibit its running mechanism. The performance of the algorithm is tested through test problems in two conditions, i.e. incompatible task sets are considered and not considered, and computational results are presented for the first time. The results indicate that NSACO has a promising solution capacity.
\end{abstract}

Keywords: Assembly line balancing, Mixed-model, Two-sided lines, Incompatible task set constraints, Nondominated sorting ant colony optimization

\section{$\ddot{0} \mathrm{z}$}

İki-taraflı montaj hatları otomotiv endüstrisinde otobüs, kamyon ve otomobil gibi geniș hacimli ürünlerin üretiminde yoğunlukla kullanılmaktadır. Karışık modelli hatlar ise üreticilere müsterilerin kișiselleștirilmiș talebini uygun maliyetle ve istenen kalitede ulaștırmak için yardımcı olmaktadır. Bu çalışma uyumsuz iş gruplarını içeren karışı-modelli iki taraflı montaj hatlarını konu almaktadır ve hat etkinliğini maksimize etmek için birbiriyle çelişen iki amacı (çevrim zamanı ve istasyon sayısı) minimize eden yeni biryöntem önermektedir. Böyle bir yaklașım montaj hattı alanında tip-E olarak adlandırılan probleme işaret etse de önerilen bastırılmamış sınıflandırmalı karınca koloni algoritması (NSACO) diğer çözümleri her iki amaç açısından do bastıran çözüm seti sunmaktadır (pareto yüzey çözümler). Çözümler arasından en yüksek hat etkinliğine sahip olanı en iyi çözüm olarak belirlenmektedir. Íki farklı çözüm her iki amaç açısından da aynı değerlere sahip olduğu zaman, ilave bir performans kriteri uygulanmaktadır. Her iki amaç da aynı değerlere sahip olduğu zaman daha düzgün iş yükü dağılımına sahip olan çözüm tercih edilmektedir. NSACO tanımlanmıștır ve çalıșma prensibi bir sayısal örnek üzerinden anlatılmıştır. Algoritmanın performansı, uyumsuz iş seti kısıtlarını dikkate alarak ve almayarak iki durum altında test edilmiștir ve araştırma sonuçları ilk defa sunulmuştur. Sonuçlar göstermektedir ki NSACO ümit verici çözüm kapasitesine sahiptir.

Anahtar kelimeler: Montaj hattı dengeleme, Karışık-model, İki taraflı hatlar, Uyumsuz iș seti kısıtları, Bastırılmamıș sınıflandırmalı karınca koloni optimizasyonu

\section{Introduction}

An assembly line is a sequential order of workstations linked to each other via a conveyor or moving belt. Each workstation performs a set of job pieces, called tasks, assigned to it within a predetermined time, called cycle time [1],[2]. Assembly line balancing problem is determining the configuration for assignment of tasks to workstations in such a way that a performance criterion (or sometimes more than one criterion) is optimised. There are essential constraints which must be ensured during the balancing process, i.e. assignment constraint, capacity constraint and precedence relationship constraint [3]. Assembly line balancing problems can be classified as type-I, type-II and type-E based on the performance criterion, or objective, sought. The number of workstations is minimised given cycle time in type-I problems whereas cycle time is minimised given the number of workstations in type-II problems. The two conflicting objectives, namely cycle time and the number of workstations, are minimised concurrently in type-E problems [4]. Assembly line balancing problems are also divided into two groups based on the configuration of workstations across the line, (i) onesided lines and, (ii) two-sided lines. In one-sided lines, workstations are located in only one side of the line, i.e. left or right. On the other hand, workstations are located on both left and right sides of the line in two-sided lines. Therefore, another constraint, operation side constraint, needs to be considered in two-sided lines which makes problem even harder to solve in compare with one-sided lines. In two-sided lines, workstations facing each other are called mated-stations. The minimisation of the number of mated-stations, which corresponds to the length of the line, is also considered as a performance criterion in two-sided lines [5].

Mixed-model lines have emerged as a response to the effort of meeting customized demands at a reasonable cost. The main advantage of a mixed-model line over a single-model line is that more than one model of a product can be assembled on the same line in an inter-mixed sequence [6],[7]. No setup is needed (or it is negligible) between model changes as models are similar to each other. Mixed-model line balancing problem was 
introduced by Thomopoulos [8] and attracted many researchers to this domain. Several exact and approximate (heuristic/metaheuristic) solution techniques have been proposed to deal with it considering various objectives and constraints. One can refer to Boysen, Fliedner [9], Battaïa and Dolgui [1] for a comprehensive classification scheme for assembly line balancing problems and solution methods presented. Specifically, Emde, Boysen [10] provided a computational evaluation of objectives to smoothen workload in mixed-model lines.

Two-sided lines are frequently used in producing homogeneous large-sized products, such as buses, trucks and automobiles, in mass quantities [11]. The two-sided line balancing problem was introduced by Bartholdi [12]. This was followed by many researchers and the problem has been dealt in various aspects. Abdullah Make, Ab. Rashid [13] presented a review of optimization methods, objective functions, and specific constraints used in solving two-sided assembly line balancing problems. The majority of the researches on twosided assembly line balancing problem focused on single-model production, see for example Kim, Kim [14], Lee, Kim [15], Kim, Song [16], Ozcan and Toklu [17], Ozbakir and Tapkan [18], Purnomo, Wee [19] and Li, Tang [20]. However, mixed-model lines are also utilised frequently in industry though they have been received less attention.

The mixed-model two-sided assembly line balancing problem (MTALBP) was introduced by Simaria and Vilarinho [21]. Ozcan and Toklu [22] presented a mathematical model and a simulated annealing algorithm for the solution of the problem. Chutima and Chimklai [23] developed a particle swarm optimisation algorithm with negative knowledge. Rabbani, Moghaddam [24] dealt with a mixed-model two-sided line configured as a multiple U-shaped layout. Kucukkoc and Zhang [7] introduced the problem of balancing and sequencing mixedmodel parallel two-sided lines, modelled the problem mathematically [25] and proposed a new hybrid genetic - ant colony algorithm approach [26] for solving the problem.

The incompatible task set (ITS) concept was introduced by Zhang, Kucukkoc [27] through a case study for rebalancing (i.e. minimisation of the cycle time). Though, no comprehensive research results were presented. Kucukkoc [28] proposed an ant colony algorithm approach for solving the MTALBP multi-objectively. ITS constraint was not incorporated in that research. Building on the work of Kucukkoc [28], Kucukkoc [29] handled the MTALBP and proposed a nondominated sorting approach for solving the problem multi-objectively again with no consideration of ITS.

This research differs from the studies existing in the literature by presenting the first computational test results for mixedmodel two-sided assembly line balancing incorporating incompatible task sets. Incompatible task set constraint is different from negative zoning constraints as will be explained in Section 2. The main contribution of this paper is the newly proposed running mechanism of a competitive ant colony optimisation algorithm for multi-objectively solving the MTALBP under the ITS constraints.

The next section briefly describes the problem studied, followed by the detailed description of the proposed NSACO algorithm in Section 3. A numerical example is provided in Section 4, in which the steps of the NSACO is explained. The results of the computational tests are reported in Section 5 and finally, the conclusions are drawn in Section 6.

\section{Problem statement}

MTALBP is to find the best assignment configuration of tasks in mixed-model two-sided lines in such a way that one or more performance criterion is optimised. The performance criteria to be optimised within the scope of this paper are cycle time, the number of mated stations/workstation and smoothness index. As the major contribution of this paper is on the methodology side, the problem definition part will be given very briefly.

A mixed-model two-sided line has workstations located on both of its sides (left and right) to build similar-models $(m=1,2, \ldots, M)$ of a product in an intermixed sequence. There is no setup between model changes and the models can be produced as low as single lots. Each workstation $(k=1,2, \ldots, N S)$ is responsible for completing a set of tasks $(i=$ $1,2, \ldots, I)$ assigned to it within certain amount of time, called cycle time $(C)$. Cycle time is determined dividing the planning horizon by the total demand for models required by the customers within this horizon. Each task requires a deterministic operation (or processing) time $\left(t_{i m}\right)$, which may vary from one model to another. There are precedence relationships between tasks caused by the technological or organisational constraints. $P_{i}$ denotes the set of predecessors of task $i$. For example, $P_{9}=\{2,6\}$ means that tasks 2 and 6 must be completed to initialise task 9 . The capacity and operation side constraints also exist in the problem. The capacity constraint ensures that there is no workstation filled by tasks of which the sum of total processing times for any model exceed the cycle time. The operation side constraint limits the assignment of tasks, in such a way that some tasks can only be assigned to left side (L) while some on the right (R). There also are some tasks that can be assigned to either side (E). Figure 1 presents the precedence relationship of a simple 9-task problem. The operation sides and processing times of tasks are given over nodes in the format " $(\mathrm{X}, \mathrm{Y}, \mathrm{Z})$ ", where $\mathrm{X}, \mathrm{Y}$ and $\mathrm{Z}$ denote operation side, processing time for model $A$ and processing time for model $\mathrm{B}$, respectively.

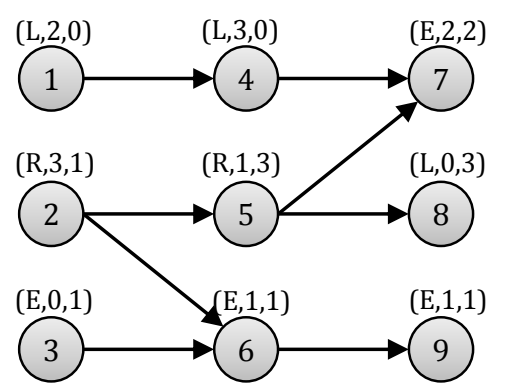

Figure 1: The precedence relationship diagram (adapted from Kim, Kim [14]).

The balancing solution of tasks is presented in Figure 2. As seen from the figure, two mated stations are utilised $(N M=2)$, consisted of a total of three workstations $(N S=3)$ under 5-unit cycle time constraint $(C=5)$. As tasks 2 and 3 must be completed before initialising task 6 , one unit idle time occurs in workstation-1. This is called sequence-dependent idle time and sometimes unavoidable due to problem specific constraints. 


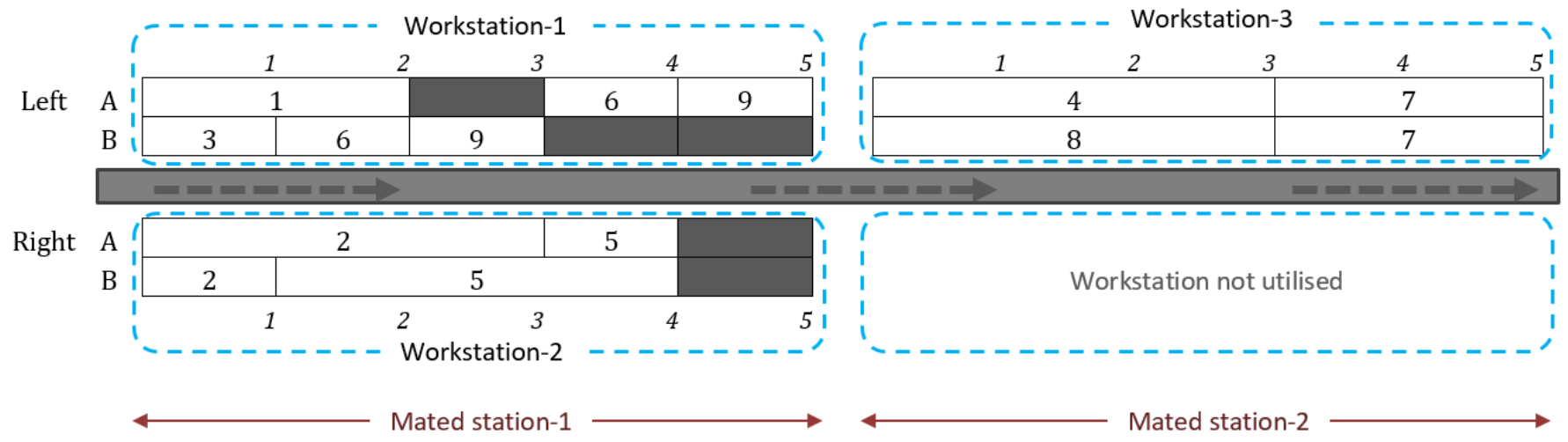

Figure 2: Balancing configuration of tasks (Ozcan and Toklu [22]).

Incompatible tasks are those tasks which cannot be performed concurrently in the same mated station (workstations located on left and right sides and facing each other). Let us assume an assembly plant producing small electrical automobiles and there are two tasks which need to be completed by operators inside the body. If the space of the body is not enough to have operators done their works, these two tasks constitute an ITS If there would be an incompatible task set such as ITS $=\{5,9\}$, the solution given in Figure 2 would not be feasible as it is not possible to perform tasks 5 and 9 for model $\mathrm{B}$ at the same time in the same mated station. However, the solution to be feasible if ITS would include tasks 2 and 9 (ITS $=\{2,9\}$ ). Note that there may be more than one ITS in the same line and each may contain different and more than two tasks.

The following section presents the proposed solution method for solving MTALBP considering ITS constraint.

\section{Nondominated sorting ant colony optimization algorithm (NSACO)}

Ant colony optimisation algorithm, developed by Dorigo, Maniezzo [30], is a well-known and powerful nature inspired technique applied widely to solving sophisticated engineering problems, especially combinatorial optimisation problems [28]. Being referred to as an NP-hard class of combinatorial optimisation problem, large-sized assembly line balancing problems require highly powerful solution techniques [25],[31], especially for large-scale instances. Therefore, an ant colony optimisation algorithm, called NSACO, is employed in this study for solving MTALBP considering ITS constraints.

The algorithm makes use of pareto front [32] approach in eliminating solutions obtained by ants in the colonies released. The objectives used by NSACO are cycle time $(C)$, the combination of the number of mated stations and workstations utilised $(S T)$ and smoothness index $(S I)$. Dominated solutions are determined based on these three factors. Thus, the best $S T$ and $S I$ values are kept for each $C$ value tested. This provides the manager of an assembly line the opportunity of choosing the best line configuration based on their cycle time, which is determined by total demand and the planning horizon. In twosided lines, the length of the line is also an important criterion different from the one-sided lines. Therefore, $N M$ is also considered in this research as an objective and $S T$ is calculated giving more importance to $N M(\mathrm{ST}=100 \times N M+N S)$.

If two or more solutions have the same $C$ and $S T$ values, then the solution which has the lower $S I$ value is favoured. This is because the smoother the workload is distributed across the workstations, the more stable the line is. $S I$ value of a solution is calculated as follows:

$$
S I=\sqrt{\sum_{m=1}^{\mathrm{M}} d_{m} \sum_{k=1}^{N S}\left(W_{m}^{\max }-W_{k m}\right)^{2}}
$$

where $W_{m}^{\max }$ is the maximum workstation workload for model $m, W_{k m}$ is the workload of workstation $k$, and $d_{m}$ is the proportional demand of model $m$, which is calculated as follows: $d_{m}=D_{m} / \sum_{m=1}^{M} D_{m}$.

The general flow of NSACO is given in Figure 3. As seen, the algorithm starts with initialising all parameters and importing problem data. $C$ is set to $C_{\text {low }}$, which is a user determined parameter, and global best solution indicators $\left(W L E^{*}, S T^{*}\right.$, and $\left.S I^{*}\right)$ are set to default values $\left(W L E^{*} \leftarrow 0\right.$, $S T^{*} \leftarrow B$ and $S I^{*} \leftarrow B$, where $B$ is a very big positive number). A new colony of ants is released and each ant in the colony builds a balancing solution, using the procedure which will be described in Figure 4. ST value is calculated and pheromone is deposited between task-workstation on the basis of the following rule:

$$
\tau_{i k} \leftarrow(1-\rho) \tau_{i k}+\Delta \tau_{i k},
$$

Where, $\Delta \tau_{i k}=Q / S T ; \rho$ and $Q$ are evaporation rate and a user determined parameter, respectively. Thus, the solution having the less $S T$ value is favoured depositing more pheromone on the edges of the shorter path.

The colony best solution is updated $\left(S T_{\text {col }} \leftarrow S T\right)$ if the $S T$ value of an individual is lower than the $S T$ value of the colony best solution $\left(S T<S T_{\text {col }}\right)$. All ants build solutions in this way. All colonies are released one-by-one and the colony best solution is added to pareto front followed by the calculation of its $W L E$ and $S I$ values. If $W L E$ of a solution is higher than the global best $W L E\left(W L E>W L E^{*}\right)$, the global best solution, $C_{\text {best }}, W L E^{*}, S T^{*}$ and $S I^{*}$ are updated $\left(C_{\text {best }} \leftarrow C, \quad W L E^{*} \leftarrow W L E, S T^{*} \leftarrow\right.$ $\left.S T_{\text {col }}, S I^{*} \leftarrow S I\right) . C_{\text {best }}$ is the cycle time value for which the best solution is found. If $W L E=W L E^{*}$ and $S I<S I^{*}$, the global best solution, $C_{\text {best }}, S T^{*}$ and $S I^{*}$ are updated $\left(C_{\text {best }} \leftarrow C, S T^{*} \leftarrow S T_{\text {col }}\right.$ and $S I^{*} \leftarrow S I$ ). In this case, there is no need to update $W L E^{*}$ as there is no change.

$W L E$ of a solution is calculated dividing the sum of the task times multiplied by proportional demands to the multiplication of cycle time and the number of workstations as follows: 


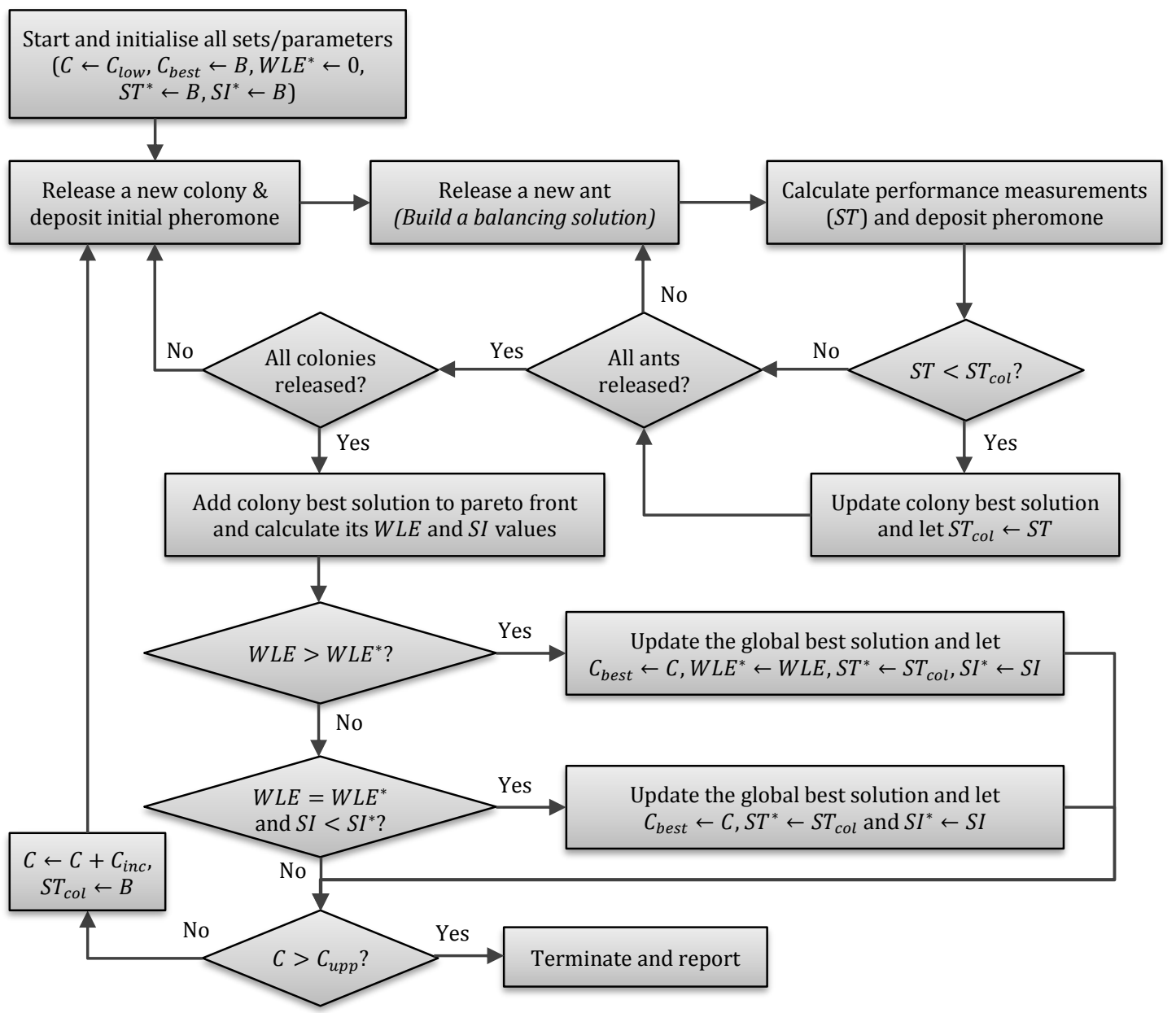

Figure 3: The general outline of NSACO.

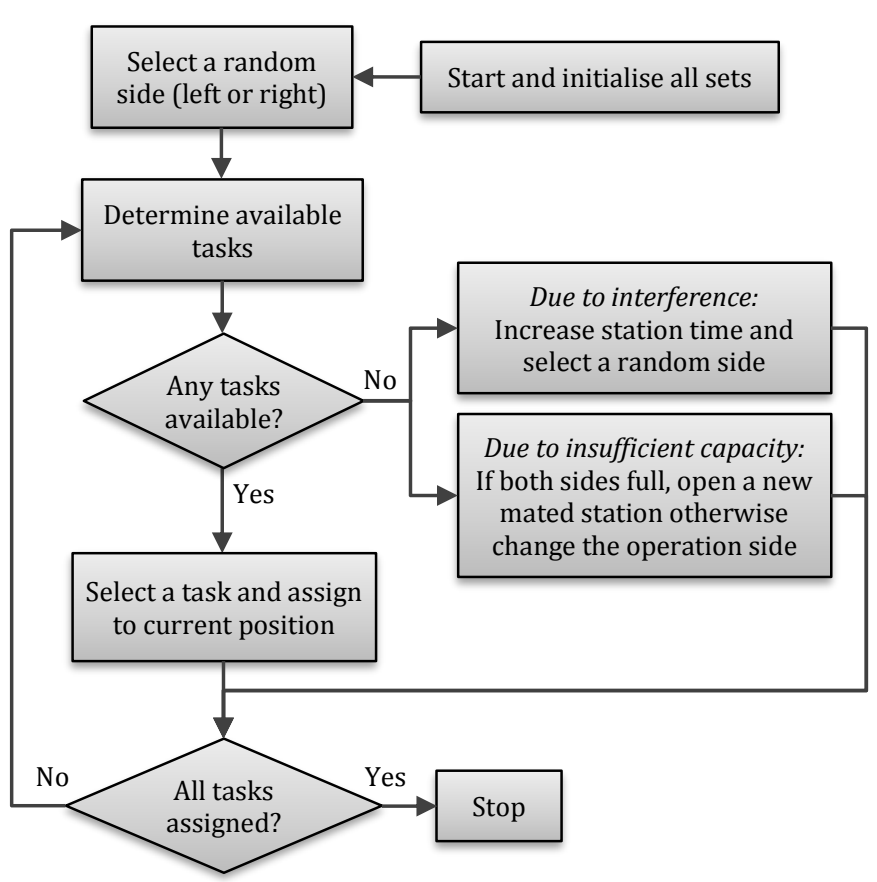

Figure 4: The procedure of building a balancing solution.

$$
\mathrm{W} L E=\frac{\sum_{m=1}^{M} \sum_{i=1}^{I} d_{m} t_{i m}}{C \times N S}
$$

Note that WLE is calculated only for colony best solutions to avoid unnecessary computation. Thus, the global best solution is determined among the pareto front solutions. $C$ is increased by $C_{i n c}\left(C \leftarrow C+C_{i n c}\right), S T_{\text {col }}$ is set to its default value $\left(S T_{c o l} \leftarrow B\right)$ and new colonies of ants are released for building new solutions considering the new $C$ value. The pheromones and best solutions are updated in the same way as above and this cycle continues until the upper bound for cycle time $\left(C_{u p p}\right)$ is achieved. The algorithm is terminated and the best solution is reported when the stopping criterion is met $\left(C>C_{\text {upp }}\right)$.

Figure 4 outlines the procedure of building a balancing solution adapted from Simaria and Vilarinho [21]. As seen, a task is selected based on a selection criterion and assigned to the current position (workstation). The selection of a task $(i)$ to a workstation $(k)$ is determined by the probability of $p_{i k}=\left(\left[\tau_{i k}\right]^{\alpha}\left[\eta_{i}\right]^{\beta}\right) /\left(\sum_{y \epsilon Z_{i}}\left[\tau_{y k}\right]^{\alpha}\left[\eta_{y}\right]^{\beta}\right)$, where $\alpha$ and $\beta$ are weighting parameters which determine the influence of pheromone and heuristic information in the task selection process, respectively [5]. $Z_{i}$ and $\tau_{i k}$ are the list of tasks available and the pheromone amount existing between task $i$ and workstation $k$, respectively. The term $\eta_{i}$ denotes the heuristic 
information for greedy search and ranked positional weight method [33] is employed for this aim.

The station time of workstation $k$ for model $m\left(s t_{k m}\right)$ is increased by the operation time of task $i\left(s t_{k m} \leftarrow s t_{\bar{k} m}+t_{i m}\right)$ and all tasks are assigned to workstations one-by-one. When there is no task available, one of the two options is selected based on the reason. If the preceding tasks assigned to the companion station prevent availability, the station time of the current station is increased for all models, $s t_{k m} \leftarrow s t_{\bar{k} m}$ (where $\bar{k}$ denotes the companion of workstation $k$ ). The procedure ends when each task is assigned to a workstation.

\section{A numerical example}

A numerical example is provided in this section to exemplify the methodology proposed. Let us assume an MTALBP consisting of 16 tasks. Table 1 presents the input data for the numerical example, taken from Ozcan and Toklu [22].

Table 1: Input data for the numerical example.

\begin{tabular}{ccccc}
\hline Task & Side & Time for A & Time for B & $\begin{array}{c}\text { Immediate } \\
\text { Predecessor(s) }\end{array}$ \\
\hline 1 & E & 6 & 0 & - \\
2 & E & 5 & 2 & - \\
3 & L & 2 & 0 & 1 \\
4 & E & 0 & 9 & 1 \\
5 & R & 8 & 0 & 2 \\
6 & L & 4 & 8 & 3 \\
7 & E & 7 & 7 & 4,5 \\
8 & E & 4 & 3 & 6,7 \\
9 & $\mathrm{R}$ & 0 & 5 & 7 \\
10 & $\mathrm{R}$ & 4 & 1 & 7 \\
11 & $\mathrm{E}$ & 6 & 3 & 8 \\
12 & $\mathrm{~L}$ & 0 & 5 & 9 \\
13 & $\mathrm{E}$ & 6 & 9 & 9,10 \\
14 & $\mathrm{E}$ & 4 & 5 & 11 \\
15 & $\mathrm{E}$ & 3 & 8 & 11,12 \\
16 & $\mathrm{E}$ & 4 & 7 & 13 \\
\hline
\end{tabular}

The algorithm is coded in Java and run on Intel Xeon CPU E3-1270 $3.5 \mathrm{GHz}$ PC with $16 \mathrm{~GB}$ of RAM using the parameters, $\alpha=0.5, \quad \beta=0.3, \quad \rho=0.1, \quad Q=50, \quad$ initial pheromone (initPher $)=30$, maximum number of colonies $(\operatorname{maxCol})=20$ and colony size $($ colsize $)=10$, determined based on preliminary tests. $C_{i n c}=1$ and both models have the same proportional demand $\left(d_{A}=d_{B}\right)$. Lower and upper bound for cycle time are assumed to be $C_{\text {low }}=14$ and $C_{\text {upp }}=24$. The range between $C_{\text {low }}$ and $C_{\text {upp }}$ is kept large to have a more inclusive example in terms of the visualisation of the results. The incompatible task set is ITS $=\{15,16\}$, which means these two tasks cannot be handled concurrently in the same mated station.

Table 2 reports the best solution obtained for each $C$ value through the iterations in which $C$ is increased by $C_{\text {inc }}=1$ starting from $C=14$. As seen from the table, the solution found in the first step for $C=14$ requires four mated stations and 7 workstations $(N M=4$ and $N S=7)$ while the lower bound is $N M=3$ and $N S=6$. The $W L E \%$ and $S I$ values of this solution are calculated as 68.88 and 9.38, respectively. In step 2, $C$ is increased to 15 and a solution is obtained requiring one lower workstation, which increases the $W L E \%$ to 75.00 . The best solution having the highest $W L E \%$ is obtained for $C=21$ (in step 8) for which the optimal number of mated stations and workstations are investigated by NSACO as $N M=2$ and $N S=$ 4. The pareto front chart of the solutions obtained is presented in Figure 5. The blue points denote the nondominated solutions while the best solution among them is obtained at $C=21$ and identified in green.

Table 2: The best solutions obtained for different cycle time values.

\begin{tabular}{cccccc}
\hline Step & $C$ & $L B$ & $N M[N S]$ & $W L E \%$ & $S I$ \\
\hline 1 & 14 & $3[6]$ & $4[7]$ & 68.88 & 9.38 \\
2 & 15 & $3[5]$ & $4[6]$ & 75.00 & 8.74 \\
3 & 16 & $3[5]$ & $4[6]$ & 70.31 & 8.34 \\
4 & 17 & $3[5]$ & $4[6]$ & 66.17 & 8.34 \\
5 & 18 & $2[4]$ & $3[5]$ & 75.00 & 12.00 \\
6 & 19 & $2[4]$ & $3[5]$ & 71.05 & 9.89 \\
7 & 20 & $2[4]$ & $3[5]$ & 67.50 & 8.94 \\
8 & 21 & $2[4]$ & $2[4]$ & $\mathbf{8 0 . 3 5}$ & 9.56 \\
9 & 22 & $2[4]$ & $2[4]$ & 76.70 & 8.33 \\
10 & 23 & $2[4]$ & $2[4]$ & 73.37 & 7.04 \\
11 & 24 & $2[3]$ & $2[4]$ & 70.31 & 7.31 \\
\hline \multicolumn{5}{c}{ Pareto Front }
\end{tabular}

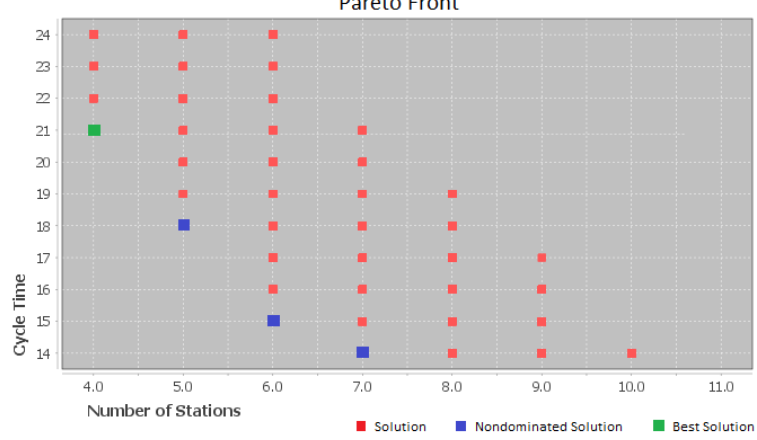

Figure 5: The pareto front diagram of the solutions obtained.

The detailed balancing configuration of tasks for this solution is depicted in Figure 6. As seen from the figure, task 16 starts in workstation- 4 after task 15, which is performed on the other side of the line (see workstation-3) for both models (A and B). If no ITS constraint was subject to consideration during the balancing solution, a slightly different balancing configuration having a smoother workload distribution could be obtained with $W L E \%=80.35$ and $S I=9.35(<9.56)$.

\section{Computational tests}

This section reports the results of the computational tests conducted through solving test problems derived/adapted from the literature using the proposed solution approach, NSACO. The tests have been performed under two conditions:

- Incompatible task set constraints are not considered (called con-I),

- Incompatible task set constraints are considered (called con-II).

In con-I, the aim is to measure the performance of NSACO, by solving the test problems whose results have been published in the literature. This is because no comparable result was published in the literature when incompatible task set constraints have been considered.

\subsection{Results achieved for con-I}

There are no results published regarding the MTALBP considering incompatible task set constraints in the literature. 


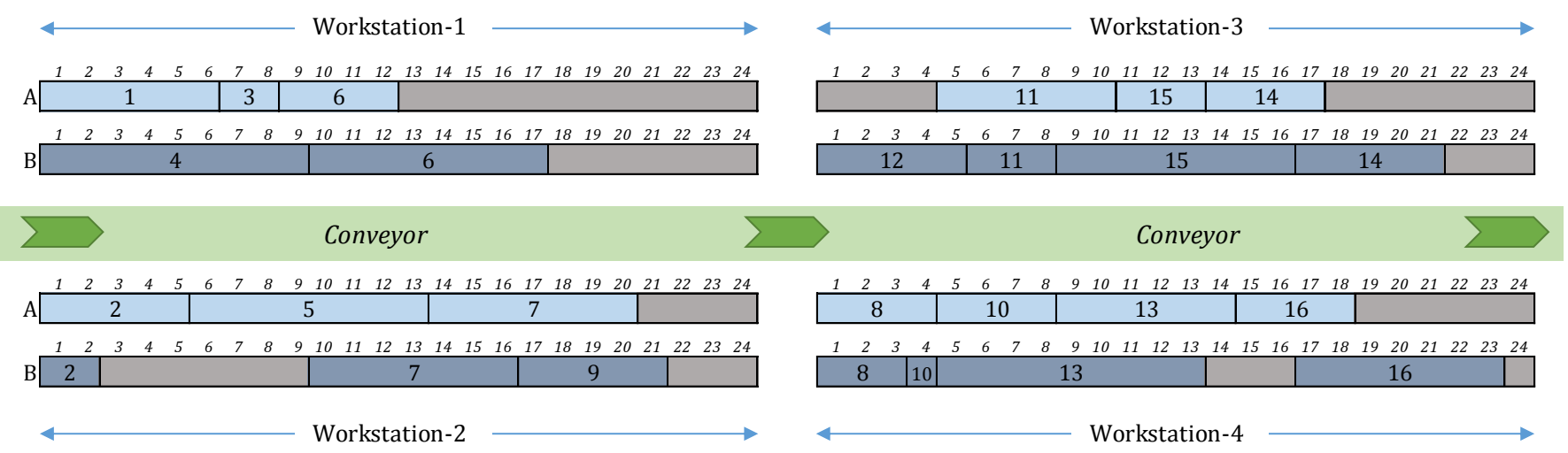

Figure 6: The best balancing solution under the ITS constraint.

Therefore, benchmarks derived and solved by Ozcan and Toklu [22] have been solved using NSACO to measure its performance. The algorithm has been coded in JAVA and run on Intel Xeon CPU E3-1270 3.5 GHz PC with 16 GB of RAM. The parameters are selected based on preliminary tests and similar studies in the literature. Some parameters are the same for all test problems $(\alpha=0.5, \quad \beta=0.3, \quad \rho=0.1, \quad Q=50$ and initPher $=30$. However, $\operatorname{maxCol}$ and colSize are increased in parallel to the increasing problem complexity caused by the growing problem size. Therefore, maxCol and colSize are set to 20 and 10 for test problems P9, P12 and P16; 30 and 15 for test problems P20, P24 and P36; and 40 and 20 for test problems P65, P148 and P205, respectively. $C_{\text {inc }}$ is assumed to be ' 1 ' for test problems P9, P12, P16, P20, P24 and P36; and '5' for test problems P65, P148 and P205. The proportional demands of the models are assumed to be the same for all test problems $\left(d_{A}=d_{B}=\cdots=d_{M}\right)$.

Table 3 presents data for the test problems and reports the results of the computational tests when incompatible task group constraints are not considered. The precedence relationships and operation directions of P9, P12 and P24 are taken from Kim, Kim [14]. Those data for P16, P65 and P205 are taken from Lee, Kim [15] and for P148 are taken from Bartholdi [12]. The task processing times of P9, P12, P16, P24, P65 and P148 are retrieved from Ozcan and Toklu [22]. P205 was not solved by Ozcan and Toklu [22], therefore task times for this problem are taken from Kucukkoc [34]. Two other test problems P20 and P36, have also been considered in the current study in addition to those in Ozcan and Toklu [22]. All data required for P20 and P36 are gathered from Kucukkoc and Zhang [26].

Each test problem has been solved using NSACO considering a lower and an upper bound for the cycle time $\left(C_{\text {low }}\right.$ and $C_{u p p}$, respectively). These values have been given as an input to the algorithm and the solution with the best $W L E \%$ value is reported as the best solution. $C_{\text {best }}$ denotes the cycle time value for which the best solution is investigated. $N M[N S]_{3}$ column reports the number of mated-stations $(N M)$ and the number of workstations $(N S)$ required for the best solution. $L B_{C}$ is the lower bound of $N M[N S]_{3}$ under the condition that the cycle time is $C_{\text {best }} . L B_{C}$ is calculated using the formulae provided by Ozcan and Toklu [22]. Thus, it is possible to make a direct comparison between $L B_{C}$ and $N M[N S]_{3}$ to measure the performance of the algorithm. When making such a comparison, it should be noted here that the solution is optimal if $N M[N S]_{3}$ is equal to $L B_{C}$. The reason lying behind this idea is that it is not theoretically possible to have a solution less than $L B_{C}$ number of $N M$ and $N S$ under the condition that cycle time is $C_{\text {best }}$.

It should be noted here that Ozcan and Toklu [22] have not handled the MTALBP with the aim of optimising cycle time as well as the number of workstations. For each test problem, Ozcan and Toklu [22] reported the number of mated-stations and the number of stations (given different cycle times in each case) found by mixed integer programming (MIP) model and simulated annealing (SA) algorithm. Therefore, the problem addressed by Ozcan and Toklu [22] is referred to as a type-I problem while the current work deals with type-E MTALBP for which cycle time is incremented by $C_{i n c}$ within an interval between $C_{\text {low }}$ and $C_{\text {upp }}$. Thus, it is not possible to make a direct comparison to Ozcan and Toklu [22]. However, the results reported by Ozcan and Toklu [22] have also been presented in Table 3 to have an idea on the overall performance of the proposed NSACO algorithm. One can compare the $W L E$ value of the best solution obtained by NSACO with the best $W L E$ value reported by Ozcan and Toklu [22]. Note that NSACO can find the best solution for a cycle time value not tested by Ozcan and Toklu [22], which is basically an advantage of the proposed approach. This is because it is not needed to test different cycle time values manually as NSACO increments it by $C_{\text {inc }}$, systematically. It is also worthy to declare that $N M[N S]_{1}$ values are the same with $N M[N S]_{2}$ for those cases solvable by MIP model reported by Ozcan and Toklu [2]. This shows how competitive the SA proposed by Ozcan and Toklu [2] is.

As seen from the table, NSACO finds solutions having the same $W L E$ values $(87.50,80.35$ and 89.28$)$ with MIP and SA for P12, $\mathrm{P} 16$ and $\mathrm{P} 24$, respectively. For P65, the $W L E$ value found by NSACO (84.76) is the same with MIP and SA when cycle time is considered as 490 . However, MIP and SA found the best $W L E$ for the cycle time value of 326 , which is skipped by NSACO. This is because NSACO starts with $C_{\text {low }}=180$, increments by $C_{i n c}=5$ in each iteration, and tries $C=325$ and $C=330$, but not $C=326$. As for P9 and P148, NSACO investigates better $W L E$ values ( 89.28 and 80.90 , respectively) for cycle times not tested by Ozcan and Toklu [22]. While this does not mean that NSACO outperforms SA, it clearly shows the powerful solution building capacity of NSACO and the nondominated sorting solution methodology proposed in this research. When the $N M[N S]_{3}$ values are compared to $L B_{C}$, it is observed that NSACO obtains optimal solutions for P9, P12, P16, P20, P24, P36 and P65. For P148, the solution found by NSACO requires one more workstation than the theoretical lower bound while 
this does not always mean that the solution is not optimal. NSACO solves P205 with requiring eight more workstations than the lower bound, which still seems reasonable considering similar studies in the literature and the growing search space with increasing number of tasks.

\subsection{Results achieved for con-II}

In con-II, ITS constraints have been included in the problem sets and the problems were solved using NSACO method on the same computer using the same parameters with con-I. The precedence relationships and operation sides have been kept the same as in con-I. However, some changes have been done in the number of models considered and the processing times of tasks. That information has been taken from Kucukkoc [34] and presented in Appendix for interested readers and researchers.
The proportional demands of the models are assumed to be the same for all test problems $\left(q_{A}=q_{B}=\cdots=q_{M}\right)$. The results of the computational tests have been reported in Table 4 . In addition to those columns given in Table 3 , three new columns have been added in Table 4 , which are incompatible task set (ITS), maximum task processing time $\left(\max \left\{t_{i m}\right\}\right)$ and the cycle time increment value $\left(C_{i n c}\right)$. ITS column shows tasks which cannot be performed at the same time in the same matedstation for the corresponding test problem. The algorithm starts with $C=C_{\text {low }}$, finds solutions releasing colonies of ants, increments $C$ by $C_{i n c}$ and repeats this until $C=C_{u p p}$. The solution with the highest $W L E \%$ value is reported, where $C_{\text {best }}$ is the cycle time for which the best solution is found. $L B_{C}$ is the lower bound for $N M[N S]$ given the cycle time is $C_{\text {best }}$.

Table 3: Computational test results for con-I.

\begin{tabular}{|c|c|c|c|c|c|c|c|c|c|c|c|c|c|}
\hline \multirow{3}{*}{ Problem } & \multirow{3}{*}{ M } & \multicolumn{5}{|c|}{ Ozcan and Toklu [22] } & \multirow{2}{*}{\multicolumn{6}{|c|}{$\begin{array}{c}\text { Current Work } \\
\text { NSACO } \\
\end{array}$}} & \multirow[b]{3}{*}{$\begin{array}{c}C P U \\
\left(x 10^{3} \mathrm{~ms}\right) \\
\end{array}$} \\
\hline & & \multirow[b]{2}{*}{ C } & \multirow[b]{2}{*}{$L B$} & \multicolumn{3}{|l|}{ MIP } & & & & & & & \\
\hline & & & & $N M[N S]_{1}$ & $N M[N S]_{2}$ & $W L E \%$ & \multirow[t]{2}{*}{$C_{\text {low }}$} & \multirow[t]{2}{*}{$C_{u p p}$} & $C_{\text {best }}$ & $L B_{C}$ & $N M[N S]_{3}$ & $W L E \%$ & \\
\hline \multirow{3}{*}{ P9 } & \multirow{3}{*}{2} & 4 & 4 & $3[4]$ & $3[4]$ & 78.12 & & & & & & & \\
\hline & & 5 & 3 & $2[3]$ & $2[3]$ & 83.33 & \multirow[t]{2}{*}{4} & \multirow[t]{2}{*}{7} & \multirow[t]{2}{*}{7} & \multirow{2}{*}{$1[2]$} & \multirow[t]{2}{*}{$1[2]$} & \multirow[t]{2}{*}{89.28} & \multirow[t]{2}{*}{66} \\
\hline & & 6 & 3 & $2[3]$ & $2[3]$ & 69.44 & & & & & & & \\
\hline \multirow{4}{*}{ P12 } & & 5 & 5 & $3[5]$ & $3[5]$ & 84.00 & & & & & & & \\
\hline & 2 & 6 & 4 & $2[4]$ & $2[4]$ & 87.50 & 4 & 7 & 6 & $2[4]$ & $2\lceil 4\rceil$ & 87.50 & 113 \\
\hline & 2 & 7 & 3 & $2[4]$ & $2[4]$ & 75.00 & 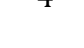 & r & 0 & $2\left[{ }^{4}\right]$ & $2\left[{ }^{4}\right]$ & 01.00 & 110 \\
\hline & & 8 & 3 & $2[3]$ & $2[3]$ & 87.50 & & & & & & & \\
\hline & & 15 & 5 & $4[6]$ & $4[6]$ & 75.00 & & & & & & & \\
\hline & & 16 & 5 & $4[6]$ & $4[6]$ & 70.31 & & & & & & & \\
\hline P16 & 2 & 18 & 4 & $3[5]$ & $3[5]$ & 75.00 & 14 & 24 & 21 & $2\lceil 4]$ & $2[4]$ & 8035 & 533 \\
\hline 110 & 2 & 19 & 4 & $3[5]$ & $3[5]$ & 71.05 & $1 \mathrm{~T}$ & $2 T$ & 21 & $2[T]$ & $2[\mathrm{~T}]$ & 00.05 & ענס \\
\hline & & 21 & 4 & $2[4]$ & $2[4]$ & 80.35 & & & & & & & \\
\hline & & 22 & 4 & $2[4]$ & $2[4]$ & 76.40 & & & & & & & \\
\hline $\mathrm{P} 20$ & 2 & - & - & - & - & - & 12 & 24 & 18 & $3[5]$ & $3[5]$ & 80.55 & 598 \\
\hline & & 20 & 7 & $4[7]$ & $4[7]$ & 89.28 & & & & & & & \\
\hline & & 24 & 6 & $3[6]$ & $3[6]$ & 86.80 & & & & & & & \\
\hline P24 & 2 & 25 & 5 & $3[6]$ & $3[6]$ & 83.33 & 16 & 35 & 35 & $2[4]$ & $2[4]$ & 89.28 & 1612 \\
\hline 124 & 2 & 30 & 5 & $3[5]$ & $3[5]$ & 83.33 & 10 & 35 & 35 & $2[4]$ & $2[4]$ & 09.20 & 1012 \\
\hline & & 35 & 4 & $2[4]$ & $2[4]$ & 89.28 & & & & & & & \\
\hline & & 40 & 4 & $2[4]$ & $2[4]$ & 78.12 & & & & & & & \\
\hline P36 & 2 & - & - & - & - & - & 16 & 35 & 34 & $3[5]$ & $3[5]$ & 87.35 & 2805 \\
\hline & & 326 & 8 & - & $5[9]$ & 84.93 & & & & & & & \\
\hline & & 381 & 7 & - & $4[8]$ & 81.75 & & & & & & & \\
\hline P65 & 3 & 435 & 6 & - & $4[7]$ & 81.83 & 310 & 560 & 490 & $3[6]$ & $3[6]$ & 84.76 & 14574 \\
\hline & & 490 & 6 & - & $3[6]$ & 84.76 & & & & & & & \\
\hline & & 544 & 5 & - & $3[6]$ & 76.34 & & & & & & & \\
\hline & & 204 & 13 & - & $9[17]$ & 75.81 & & & & & & & \\
\hline & & 255 & 11 & - & $7[14]$ & 73.64 & & & & & & & \\
\hline & & 306 & 9 & - & $6[12]$ & 71.60 & & & & & & & \\
\hline P148 & 4 & 357 & 8 & - & $5[10]$ & 73.64 & 180 & 510 & 325 & $5[9]$ & $5[10]$ & 80.90 & 107868 \\
\hline & & 408 & 7 & - & $5[10]$ & 64.44 & & & & & & & \\
\hline & & 459 & 6 & - & $4[8]$ & 71.60 & & & & & & & \\
\hline & & 510 & 6 & - & $4[8]$ & 64.44 & & & & & & & \\
\hline P205 & 3 & - & - & - & - & - & 550 & 1020 & 755 & $20[40]$ & $25[48]$ & 72.47 & 132426 \\
\hline
\end{tabular}


Table 4: Results of the computational tests for con-II.

\begin{tabular}{|c|c|c|c|c|c|c|c|c|c|c|}
\hline Problem & M & ITS & $\max \left\{t_{i m}\right\}$ & $C_{\text {low }}$ & $C_{u p p}$ & $C_{i n c}$ & $C_{\text {best }}$ & $L B_{C}$ & $N M[N S]_{4}$ & WLE \\
\hline P9 & 3 & $\{8,9\}$ & 4 & 4 & 7 & 1 & 6 & $2[4]$ & $2[4]$ & 72.33 \\
\hline $\mathrm{P} 12$ & 3 & $\{2,3\}$ & 3 & 4 & 7 & 1 & 6 & $2[4]$ & $3[4]$ & 87.50 \\
\hline P16 & 3 & $\{12,13\}$ & 9 & 14 & 24 & 1 & 24 & $3[5]$ & $3[5]$ & 73.55 \\
\hline $\mathrm{P} 20$ & 3 & $\{9,11\}$ & 9 & 12 & 24 & 1 & 15 & $4[7]$ & $5[7]$ & 76.04 \\
\hline $\mathrm{P} 24$ & 3 & $\{11,17\}$ & 9 & 16 & 35 & 1 & 18 & $4[8]$ & $4[8]$ & 72.47 \\
\hline P36 & 3 & $\{2,3\},\{30,32\}$ & 9 & 16 & 35 & 1 & 30 & $3[6]$ & $3[6]$ & 81.04 \\
\hline P65 & 3 & $\{2,3,13\},\{12,43,46\}$ & 272 & 300 & 550 & 5 & 505 & $6[11]$ & $7[13]$ & 80.40 \\
\hline P148 & 3 & $\{56,74,93\},\{115,124,130\}$ & 170 & 180 & 485 & 5 & 450 & $11[22]$ & $12[24]$ & 70.81 \\
\hline P205 & 3 & $\{42,63,70\},\{156,160\}$ & 452 & 490 & 800 & 5 & 765 & $20[39]$ & $27[49]$ & 70.06 \\
\hline
\end{tabular}

From the comparison of $L B_{C}$ and $N M[N S]_{4}$ columns, NSACO found optimal solutions in terms of the $N S$ values for test problems P9, P12, P16, P20, P24 and P36. For the remaining ones, i.e. P65, P148 and P205, NSACO finds 2, 2 and 10 more workstations than the lower bound, respectively. The gap gets bigger in P205, which seems reasonable considering the large number of tasks subject to balancing. It is also worthy to express that the optimal solutions tend to have more number of workstations than the lower bound when the problem size increases.

The weighted line efficiency values reported in $W L E \%$ column are different from those reported for con-I. This is caused by the fluctuation in the task processing times between the models. As the processing times are generated randomly, they show considerable variation in comparison to those used in con-I (see Appendix). However, finding optimal solutions as discussed above indicates that NSACO has a promising solution building capacity for MTALBP with and without ITS constraints.

\section{Conclusions}

This paper addressed to the MTALBP considering ITS constraints and reported the first research results. MTALBP has NP-hard complexity and is hard to optimally solve the largesized instances using traditional methods. Therefore, a nondominated sorting solution approach is proposed for the solution of the problem. Three important performance criteria have been considered in the solution method, i.e. cycle time, the number of mated stations/workstations, and smoothness index. The proposed method, NSACO, has been described and a numerical example has been solved to exhibit the solution mechanism of the proposed methodology. The best solution obtained for the numerical example is depicted in details and the pareto front diagram is presented highlighting nondominated solutions. The best solution among the nondominated solutions is identified based on the $W L E \%$ value. When there is more than one solution having the same $W L E \%$ value, the solution having the smaller $S I$ value is chosen. Test problems have been derived from the literature and solved under two conditions: ITS constraints were considered and not considered. The results obtained when ITS constraints were not considered have been compared to the results existing in the literature and it was observed that NSACO performs quite well. The results obtained when ITS constraints were considered have been presented and compared to the lower bounds. The comparison indicated that NSACO has quite promising solution capacity.

The problem and the solution method proposed in this research can be extended in several ways. As the MTALBP relates to a real-world industrial engineering problem, the managers of assembly lines used for producing large-sized products can easily adopt the concept proposed in this paper to their problems. Also, researchers studying on line balancing problems can adopt the ITS constraint to other problem types, such as U-shaped lines and parallel lines with two sides. Furthermore, researchers interested in this topic can use the results reported as a benchmark for their research. New solution methods (exact or approximate) can be developed for MTALBP with ITS constraints and their performances can be compared to NSACO solving the test problems, for which the input data have been provided in Appendix.

\section{References}

[1] Battaïa 0, Dolgui A. "A taxonomy of line balancing problems and their solution approaches". International Journal of Production Economics, 142(2), 259-277, 2013.

[2] Kucukkoc I, Zhang DZ. "Balancing of parallel U-shaped assembly lines". Computers and Operations Research, 64, 233-244, 2015.

[3] Diri Z, Mete S, Çil ZA, Ağpak K. "Assembly Line Balancing Problem with Stochastic Sequence-Dependent Setup Times". Pamukkale University Journal of Engineering Sciences, 21(4), 152-157, 2015.

[4] Kucukkoc I, Zhang DZ. "Type-E parallel two-sided assembly line balancing problem: Mathematical model and ant colony optimisation based approach with optimised parameters". Computers and Industrial Engineering, 84, 56-69, 2015.

[5] Kucukkoc I, Zhang DZ. "Mixed-model parallel two-sided assembly line balancing problem: A flexible agent-based ant colony optimization approach". Computers \& Industrial Engineering, 97, 58-72, 2016.

[6] Kucukkoc I, Buyukozkan K, Satoglu SI, Zhang DZ. "A mathematical model and artificial bee colony algorithm for the lexicographic bottleneck mixed-model assembly line balancing problem". Journal of Intelligent Manufacturing, 1-13, 2015.

[7] Kucukkoc I, Zhang DZ. "Simultaneous balancing and sequencing of mixed-model parallel two-sided assembly lines". International Journal of Production Research, 52(12), 3665-3687, 2014. 
[8] Thomopoulos NT. "Line balancing-sequencing for mixedmodel assembly". Management Science, 14(2), 59-75, 1967.

[9] Boysen N, Fliedner M, Scholl A. "A classification of assembly line balancing problems". European Journal of Operational Research, 183(2), 674-693, 2007.

[10] Emde S, Boysen N, Scholl A. "Balancing mixed-model assembly lines: a computational evaluation of objectives to smoothen workload". International Journal of Production Research, 48(11), 3173-3191, 2010.

[11] Baykasoglu A, Dereli T. "Two-sided assembly line balancing using an ant-colony-based heuristic". International Journal of Advanced Manufacturing Technology, 36(5-6), 582-588, 2008.

[12] Bartholdi JJ. "Balancing 2-Sided Assembly Lines - a CaseStudy". International Journal of Production Research, 31(10), 2447-2461, 1993.

[13] Abdullah Make MR, Ab. Rashid MFF, Razali MM. "A review of two-sided assembly line balancing problem". The International Journal of Advanced Manufacturing Technology, 89(5-8), 1743-1763, 2017

[14] Kim YK, Kim YH, Kim YJ. "Two-sided assembly line balancing: a genetic algorithm approach". Production Planning \& Control, 11(1), 44-53, 2000.

[15] Lee TO, Kim Y, Kim YK. "Two-sided assembly line balancing to maximize work relatedness and slackness". Computers \& Industrial Engineering, 40(3), 273-292, 2001.

[16] Kim YK, Song WS, Kim JH. "A mathematical model and a genetic algorithm for two-sided assembly line balancing". Computers \& Operations Research, 36(3), 853-865, 2009.

[17] Ozcan U, Toklu B. "A tabu search algorithm for two-sided assembly line balancing". International Journal of Advanced Manufacturing Technology, 43(7-8), 822-829, 2009.

[18] Ozbakir L, Tapkan P. "Bee colony intelligence in zone constrained two-sided assembly line balancing problem". Expert Systems with Applications, 38(9), 11947-11957, 2011.

[19] Purnomo HD, Wee HM, Rau H. "Two-sided assembly lines balancing with assignment restrictions". Mathematical and Computer Modelling, 57(1-2), 189-199, 2013.

[20] Li Z, Tang Q, Zhang L. "Two-sided assembly line balancing problem of type I: Improvements, a simple algorithm and a comprehensive study". Computers \& Operations Research, 79, 78-93, 2017.

[21] Simaria AS, Vilarinho PM. "2-ANTBAL: An ant colony optimisation algorithm for balancing two-sided assembly lines". Computers \& Industrial Engineering, 56(2), 489-506, 2009.

[22] Ozcan U, Toklu B. "Balancing of mixed-model two-sided assembly lines". Computers \& Industrial Engineering, 57(1), 217-227, 2009.
[23] Chutima P, Chimklai P. "Multi-objective two-sided mixedmodel assembly line balancing using particle swarm optimisation with negative knowledge". Computers \& Industrial Engineering, 62(1), 39-55, 2012.

[24] Rabbani M, Moghaddam M, Manavizadeh N. "Balancing of mixed-model two-sided assembly lines with multiple Ushaped layout". International Journal of Advanced Manufacturing Technology, 59(9-12), 1191-1210, 2012.

[25] Kucukkoc I, Zhang DZ. "Mathematical model and agent based solution approach for the simultaneous balancing and sequencing of mixed-model parallel two-sided assembly lines". International Journal of Production Economics, 158, 314-333, 2014.

[26] Kucukkoc I, Zhang DZ. "Integrating ant colony and genetic algorithms in the balancing and scheduling of complex assembly lines". The International Journal of Advanced Manufacturing Technology, 82(1-4), 265-285, 2016.

[27] Zhang DZ, Kucukkoc I, Karaoglan AD. "Rebalancing of mixed-model two-sided assembly lines with incompatible task groups: An industrial case study". 46 ${ }^{\text {th }}$ International Conference on Computers \& Industrial Engineering (CIE46), Tianjin, China, 29-31 October 2016.

[28] Kucukkoc I. "Multi-objective Optimization of Mixed-model Two-sided assembly lines-a case study". International Conference on Computer Science and Engineering, Tekirdağ, Turkey, 20-23 October 2016.

[29] Kucukkoc I. "A non-dominated sorting approach to biobjective optimisation of mixed-model two-sided assembly lines". 11 th International Conference on LargeScale Scientific Computations, Sozopol, Bulgaria, 5-9 June 2017.

[30] Dorigo M, Maniezzo V, Colorni A. "Ant system: Optimization by a colony of cooperating agents". IEEE Transactions on Systems Man and Cybernetics Part BCybernetics, 26(1), 29-41, 1996.

[31] Li Z, Kucukkoc I, Nilakantan JM. "Comprehensive review and evaluation of heuristics and meta-heuristics for twosided assembly line balancing problem". Computers \& Operations Research, 84, 146-161, 2017.

[32] Deb K, Pratap A, Agarwal S, Meyarivan T. "A fast and elitist multiobjective genetic algorithm: NSGA-II". IEEE Transactions on Evolutionary Computation, 6(2), 182-197, 2002.

[33] Helgeson WB, Birnie DP. "assembly line balancing using the ranked positional weight technique". The Journal of Industrial Engineering, 12(6), 394-398, 1961.

[34] Kucukkoc I. Modelling and Solving Mixed-model Parallel Two-sided Assembly Line Problems, PhD Thesis, University of Exeter, Exeter, UK, 2015. 


\section{Appendix A}

This section presents the task times of the test problems taken from Kucukkoc [34] and used in Section 5.2.

\begin{tabular}{|c|c|c|c|c|c|c|c|c|c|c|c|c|c|c|c|c|c|c|}
\hline & & P9 & & & P12 & & & $\mathrm{P} 16$ & & & $\mathrm{P} 20$ & & & P24 & & & P3 & \\
\hline Task & A & B & C & A & B & C & A & B & C & A & B & C & A & B & C & $\mathrm{A}$ & B & C \\
\hline 1 & 2 & 4 & 2 & 3 & 2 & 2 & 6 & 7 & 6 & 4 & 7 & 3 & 3 & 3 & 0 & 9 & 5 & 4 \\
\hline 2 & 3 & 3 & 1 & 3 & 3 & 2 & 5 & 2 & 0 & 3 & 5 & 9 & 7 & 0 & 2 & 5 & 3 & 9 \\
\hline 3 & 2 & 2 & 1 & 0 & 2 & 1 & 2 & 5 & 9 & 0 & 2 & 3 & 7 & 1 & 1 & 7 & 7 & 9 \\
\hline 4 & 3 & 0 & 0 & 2 & 3 & 2 & 9 & 2 & 8 & 4 & 1 & 3 & 5 & 0 & 0 & 2 & 3 & 0 \\
\hline 5 & 4 & 2 & 3 & 2 & 1 & 2 & 8 & 9 & 5 & 1 & 2 & 2 & 4 & 6 & 1 & 6 & 4 & 5 \\
\hline 6 & 3 & 2 & 0 & 0 & 1 & 1 & 4 & 8 & 0 & 4 & 8 & 1 & 3 & 5 & 1 & 4 & 8 & 9 \\
\hline 7 & 0 & 3 & 3 & 2 & 2 & 2 & 7 & 8 & 9 & 3 & 4 & 9 & 4 & 8 & 5 & 4 & 1 & 4 \\
\hline 8 & 2 & 1 & 1 & 2 & 3 & 3 & 4 & 6 & 3 & 5 & 4 & 5 & 3 & 0 & 7 & 1 & 4 & 1 \\
\hline 9 & 1 & 2 & 2 & 1 & 2 & 1 & 5 & 0 & 8 & 7 & 7 & 6 & 6 & 4 & 4 & 0 & 6 & 2 \\
\hline 10 & & & & 3 & 2 & 1 & 4 & 4 & 7 & 8 & 3 & 0 & 4 & 2 & 9 & 8 & 5 & 3 \\
\hline 11 & & & & 2 & 0 & 1 & 6 & 5 & 7 & 2 & 6 & 3 & 4 & 8 & 3 & 0 & 8 & 0 \\
\hline 12 & & & & 1 & 1 & 2 & 5 & 6 & 6 & 1 & 6 & 5 & 3 & 1 & 1 & 6 & 5 & 0 \\
\hline 13 & & & & & & & 6 & 4 & 9 & 2 & 1 & 9 & 3 & 5 & 3 & 7 & 6 & 7 \\
\hline 14 & & & & & & & 4 & 2 & 7 & 5 & 8 & 9 & 9 & 4 & 3 & 1 & 1 & 1 \\
\hline 15 & & & & & & & 3 & 6 & 9 & 3 & 5 & 3 & 5 & 1 & 4 & 5 & 9 & 1 \\
\hline 16 & & & & & & & 4 & 8 & 8 & 2 & 1 & 4 & 9 & 1 & 2 & 6 & 5 & 7 \\
\hline 17 & & & & & & & & & & 5 & 2 & 5 & 2 & 7 & 3 & 0 & 0 & 0 \\
\hline 18 & & & & & & & & & & 0 & 8 & 6 & 7 & 4 & 4 & 7 & 3 & 1 \\
\hline 19 & & & & & & & & & & 2 & 0 & 1 & 9 & 2 & 1 & 8 & 3 & 5 \\
\hline 20 & & & & & & & & & & 4 & 0 & 9 & 9 & 1 & 1 & 2 & 2 & 3 \\
\hline 21 & & & & & & & & & & & & & 8 & 9 & 7 & 8 & 0 & 8 \\
\hline 22 & & & & & & & & & & & & & 8 & 7 & 9 & 1 & 3 & 8 \\
\hline 23 & & & & & & & & & & & & & 9 & 9 & 5 & 1 & 2 & 0 \\
\hline 24 & & & & & & & & & & & & & 9 & 3 & 5 & 7 & 1 & 8 \\
\hline 25 & & & & & & & & & & & & & & & & 5 & 1 & 3 \\
\hline 26 & & & & & & & & & & & & & & & & 5 & 0 & 6 \\
\hline 27 & & & & & & & & & & & & & & & & 9 & 0 & 0 \\
\hline 28 & & & & & & & & & & & & & & & & 1 & 3 & 5 \\
\hline 29 & & & & & & & & & & & & & & & & 2 & 6 & 8 \\
\hline 30 & & & & & & & & & & & & & & & & 5 & 0 & 5 \\
\hline 31 & & & & & & & & & & & & & & & & 5 & 1 & 4 \\
\hline 32 & & & & & & & & & & & & & & & & 0 & 5 & 1 \\
\hline 33 & & & & & & & & & & & & & & & & 7 & 8 & 1 \\
\hline 34 & & & & & & & & & & & & & & & & 7 & 4 & 7 \\
\hline 35 & & & & & & & & & & & & & & & & 8 & 7 & 3 \\
\hline 36 & & & & & & & & & & & & & & & & 8 & 1 & 2 \\
\hline
\end{tabular}

\begin{tabular}{|c|c|c|c|c|c|c|c|c|c|c|c|}
\hline \multicolumn{12}{|c|}{ Appendix B } \\
\hline P65 & & & & & & & & & & & \\
\hline Task & $\mathrm{A}$ & B & $\mathrm{C}$ & Task & $\mathrm{A}$ & B & $\mathrm{C}$ & Task & $\mathrm{A}$ & B & $\mathrm{C}$ \\
\hline 1 & 49 & 57 & 133 & 23 & 104 & 120 & 88 & 45 & 97 & 119 & 57 \\
\hline 2 & 49 & 68 & 71 & 24 & 84 & 52 & 89 & 46 & 37 & 102 & 52 \\
\hline 3 & 71 & 62 & 135 & 25 & 113 & 95 & 208 & 47 & 25 & 46 & 144 \\
\hline 4 & 26 & 145 & 110 & 26 & 72 & 9 & 5 & 48 & 89 & 118 & 50 \\
\hline 5 & 42 & 104 & 43 & 27 & 62 & 7 & 104 & 49 & 27 & 17 & 114 \\
\hline 6 & 30 & 47 & 101 & 28 & 272 & 47 & 84 & 50 & 50 & 79 & 5 \\
\hline 7 & 167 & 83 & 133 & 29 & 89 & 66 & 84 & 51 & 46 & 56 & 17 \\
\hline 8 & 91 & 95 & 126 & 30 & 49 & 127 & 63 & 52 & 46 & 140 & 94 \\
\hline 9 & 52 & 53 & 114 & 31 & 11 & 133 & 144 & 53 & 55 & 17 & 50 \\
\hline 10 & 153 & 265 & 200 & 32 & 45 & 91 & 70 & 54 & 118 & 86 & 63 \\
\hline 11 & 68 & 81 & 33 & 33 & 54 & 73 & 135 & 55 & 47 & 28 & 0 \\
\hline 12 & 52 & 64 & 29 & 34 & 106 & 128 & 268 & 56 & 164 & 39 & 65 \\
\hline 13 & 135 & 28 & 211 & 35 & 132 & 145 & 118 & 57 & 113 & 149 & 174 \\
\hline 14 & 54 & 87 & 67 & 36 & 52 & 124 & 17 & 58 & 69 & 23 & 18 \\
\hline 15 & 57 & 0 & 18 & 37 & 157 & 149 & 73 & 59 & 30 & 40 & 115 \\
\hline 16 & 151 & 86 & 58 & 38 & 109 & 141 & 90 & 60 & 25 & 48 & 84 \\
\hline 17 & 39 & 93 & 36 & 39 & 32 & 31 & 145 & 61 & 106 & 15 & 25 \\
\hline 18 & 194 & 53 & 27 & 40 & 32 & 144 & 182 & 62 & 23 & 59 & 1 \\
\hline 19 & 35 & 69 & 115 & 41 & 52 & 118 & 27 & 63 & 118 & 122 & 121 \\
\hline 20 & 119 & 86 & 15 & 42 & 193 & 256 & 103 & 64 & 155 & 44 & 108 \\
\hline 21 & 34 & 10 & 89 & 43 & 34 & 80 & 43 & 65 & 65 & 34 & 44 \\
\hline 22 & 38 & 86 & 48 & 44 & 34 & 21 & 29 & & & & \\
\hline
\end{tabular}




\section{Appendix C}

\begin{tabular}{|c|c|c|c|c|c|c|c|c|c|c|c|c|c|c|c|}
\hline P148 & & & & & & & & & & & & & & & \\
\hline Task & $\mathrm{A}$ & B & $\mathrm{C}$ & Task & $\mathrm{A}$ & B & $\mathrm{C}$ & Task & A & B & $\mathrm{C}$ & Task & $\mathrm{A}$ & B & $\mathrm{C}$ \\
\hline 1 & 16 & 24 & 69 & 38 & 80 & 84 & 84 & 75 & 101 & 165 & 129 & 112 & 162 & 128 & 87 \\
\hline 2 & 30 & 13 & 125 & 39 & 7 & 109 & 31 & 76 & 5 & 33 & 70 & 113 & 11 & 113 & 28 \\
\hline 3 & 7 & 25 & 109 & 40 & 41 & 119 & 67 & 77 & 28 & 76 & 64 & 114 & 19 & 19 & 96 \\
\hline 4 & 47 & 113 & 69 & 41 & 47 & 21 & 3 & 78 & 8 & 24 & 126 & 115 & 14 & 70 & 121 \\
\hline 5 & 29 & 16 & 63 & 42 & 16 & 25 & 95 & 79 & 111 & 43 & 149 & 116 & 31 & 80 & 36 \\
\hline 6 & 8 & 53 & 6 & 43 & 32 & 80 & 37 & 80 & 7 & 70 & 11 & 117 & 32 & 55 & 10 \\
\hline 7 & 39 & 76 & 123 & 44 & 66 & 85 & 52 & 81 & 26 & 103 & 24 & 118 & 26 & 32 & 57 \\
\hline 8 & 37 & 30 & 36 & 45 & 80 & 46 & 21 & 82 & 10 & 45 & 92 & 119 & 55 & 55 & 69 \\
\hline 9 & 32 & 60 & 88 & 46 & 7 & 33 & 121 & 83 & 21 & 68 & 114 & 120 & 31 & 100 & 3 \\
\hline 10 & 29 & 7 & 5 & 47 & 41 & 94 & 4 & 84 & 26 & 74 & 87 & 121 & 32 & 85 & 35 \\
\hline 11 & 17 & 99 & 54 & 48 & 13 & 8 & 123 & 85 & 20 & 8 & 7 & 122 & 26 & 59 & 71 \\
\hline 12 & 11 & 115 & 30 & 49 & 47 & 121 & 45 & 86 & 21 & 92 & 102 & 123 & 19 & 48 & 51 \\
\hline 13 & 32 & 120 & 35 & 50 & 33 & 0 & 28 & 87 & 47 & 6 & 4 & 124 & 14 & 45 & 32 \\
\hline 14 & 15 & 117 & 72 & 51 & 34 & 27 & 30 & 88 & 23 & 53 & 71 & 125 & 19 & 44 & 119 \\
\hline 15 & 53 & 28 & 64 & 52 & 11 & 51 & 81 & 89 & 13 & 59 & 87 & 126 & 48 & 51 & 120 \\
\hline 16 & 53 & 81 & 116 & 53 & 118 & 59 & 99 & 90 & 19 & 32 & 53 & 127 & 55 & 79 & 33 \\
\hline 17 & 8 & 43 & 2 & 54 & 25 & 49 & 41 & 91 & 115 & 0 & 25 & 128 & 8 & 109 & 43 \\
\hline 18 & 24 & 4 & 95 & 55 & 7 & 3 & 52 & 92 & 35 & 0 & 66 & 129 & 11 & 123 & 106 \\
\hline 19 & 24 & 18 & 58 & 56 & 28 & 73 & 14 & 93 & 26 & 40 & 95 & 130 & 27 & 90 & 1 \\
\hline 20 & 8 & 78 & 31 & 57 & 12 & 96 & 43 & 94 & 46 & 88 & 46 & 131 & 18 & 46 & 48 \\
\hline 21 & 7 & 61 & 68 & 58 & 52 & 49 & 110 & 95 & 20 & 60 & 72 & 132 & 36 & 3 & 119 \\
\hline 22 & 8 & 48 & 48 & 59 & 14 & 41 & 74 & 96 & 31 & 4 & 119 & 133 & 23 & 74 & 109 \\
\hline 23 & 14 & 115 & 96 & 60 & 3 & 20 & 78 & 97 & 19 & 52 & 22 & 134 & 20 & 80 & 85 \\
\hline 24 & 13 & 52 & 81 & 61 & 3 & 86 & 25 & 98 & 34 & 54 & 28 & 135 & 46 & 29 & 63 \\
\hline 25 & 10 & 123 & 124 & 62 & 8 & 32 & 129 & 99 & 51 & 29 & 91 & 136 & 64 & 78 & 91 \\
\hline 26 & 25 & 2 & 40 & 63 & 16 & 48 & 46 & 100 & 39 & 63 & 4 & 137 & 22 & 126 & 31 \\
\hline 27 & 11 & 24 & 59 & 64 & 33 & 37 & 71 & 101 & 30 & 15 & 81 & 138 & 15 & 28 & 6 \\
\hline 28 & 25 & 45 & 43 & 65 & 8 & 63 & 89 & 102 & 26 & 30 & 127 & 139 & 34 & 122 & 48 \\
\hline 29 & 11 & 47 & 80 & 66 & 18 & 121 & 57 & 103 & 13 & 57 & 47 & 140 & 22 & 54 & 42 \\
\hline 30 & 29 & 26 & 4 & 67 & 10 & 31 & 63 & 104 & 45 & 107 & 52 & 141 & 151 & 90 & 30 \\
\hline 31 & 25 & 50 & 33 & 68 & 14 & 47 & 95 & 105 & 58 & 129 & 119 & 142 & 148 & 24 & 106 \\
\hline 32 & 10 & 34 & 71 & 69 & 28 & 15 & 60 & 106 & 28 & 70 & 78 & 143 & 64 & 32 & 55 \\
\hline 33 & 14 & 29 & 92 & 70 & 11 & 45 & 97 & 107 & 8 & 67 & 80 & 144 & 170 & 37 & 9 \\
\hline 34 & 41 & 11 & 49 & 71 & 18 & 3 & 107 & 108 & 43 & 68 & 40 & 145 & 137 & 4 & 89 \\
\hline 35 & 42 & 117 & 54 & 72 & 25 & 104 & 55 & 109 & 40 & 39 & 88 & 146 & 64 & 24 & 28 \\
\hline 36 & 47 & 43 & 83 & 73 & 40 & 30 & 60 & 110 & 34 & 69 & 111 & 147 & 78 & 24 & 26 \\
\hline 37 & 7 & 91 & 34 & 74 & 40 & 97 & 1 & 111 & 23 & 103 & 75 & 148 & 78 & 86 & 111 \\
\hline
\end{tabular}

\section{Appendix D}

\begin{tabular}{|c|c|c|c|c|c|c|c|c|c|c|c|c|c|c|c|}
\hline P205 & & & & & & & & & & & & & & & \\
\hline Task & $\mathrm{A}$ & B & $\mathrm{C}$ & Task & $\mathrm{A}$ & B & $\mathrm{C}$ & Task & $\mathrm{A}$ & B & $\mathrm{C}$ & Task & A & B & $\mathrm{C}$ \\
\hline $1^{*}$ & 39 & 151 & 204 & 53 & 85 & 185 & 53 & 105 & 232 & 84 & 6 & 157 & 83 & 113 & 189 \\
\hline 2 & 42 & 104 & 75 & 54 & 43 & 49 & 34 & 106 & 122 & 396 & 410 & 158 & 35 & 84 & 35 \\
\hline 3 & 261 & 52 & 126 & 55 & 97 & 116 & 59 & 107 & 151 & 222 & 120 & 159 & 58 & 61 & 40 \\
\hline 4 & 261 & 447 & 394 & 56 & 37 & 206 & 113 & 108 & 31 & 76 & 105 & 160 & 42 & 108 & 70 \\
\hline 5 & 157 & 75 & 10 & 57 & 13 & 36 & 143 & 109 & 97 & 16 & 42 & 161 & 68 & 165 & 100 \\
\hline 6 & 90 & 7 & 139 & 58 & 35 & 73 & 299 & 110 & 308 & 426 & 429 & 162 & 68 & 139 & 74 \\
\hline 7 & 54 & 167 & 145 & 59 & 217 & 102 & 219 & 111 & 116 & 196 & 151 & 163 & 68 & 44 & 42 \\
\hline 9 & 30 & 77 & 48 & 61 & 85 & 373 & 154 & 113 & 34 & 136 & 195 & 165 & 103 & 35 & 108 \\
\hline 10 & 106 & 124 & 200 & 62 & 25 & 137 & 44 & 114 & 128 & 15 & 83 & 166 & 103 & 94 & 46 \\
\hline 11 & 32 & 34 & 89 & 63 & 37 & 210 & 89 & 115 & 54 & 89 & 3 & 167 & 103 & 87 & 58 \\
\hline 12 & 62 & 79 & 19 & 64 & 37 & 38 & 139 & 116 & 175 & 180 & 76 & 168 & 103 & 134 & 44 \\
\hline 13 & 54 & 176 & 188 & 65 & 103 & 41 & 253 & 117 & 55 & 111 & 221 & 169 & 68 & 19 & 37 \\
\hline 14 & 67 & 8 & 192 & 66 & 140 & 424 & 425 & 118 & 306 & 368 & 15 & 170 & 103 & 138 & 23 \\
\hline 15 & 30 & 116 & 172 & 67 & 49 & 59 & 152 & 119 & 59 & 198 & 122 & 171 & 68 & 28 & 5 \\
\hline 16 & 106 & 69 & 297 & 68 & 35 & 143 & 139 & 120 & 59 & 204 & 46 & 172 & 103 & 342 & 431 \\
\hline 18 & 62 & 300 & 37 & 70 & 88 & 221 & 123 & 122 & 66 & 118 & 99 & 174 & 68 & 7 & 42 \\
\hline 19 & 56 & 156 & 234 & 71 & 53 & 341 & 288 & 123 & 23 & 95 & 127 & 175 & 103 & 230 & 201 \\
\hline 20 & 67 & 35 & 224 & 72 & 144 & 301 & 102 & 124 & 244 & 250 & 50 & 176 & 103 & 185 & 139 \\
\hline 21 & 86 & 71 & 4 & 73 & 337 & 83 & 394 & 125 & 54 & 83 & 292 & 177 & 10 & 69 & 64 \\
\hline 22 & 37 & 12 & 59 & 74 & 107 & 184 & 156 & 126 & 294 & 10 & 266 & 178 & 187 & 96 & 145 \\
\hline 23 & 41 & 64 & 16 & 75 & 371 & 100 & 444 & 127 & 84 & 136 & 110 & 179 & 134 & 82 & 163 \\
\hline 24 & 72 & 105 & 3 & 76 & 97 & 276 & 11 & 128 & 61 & 113 & 127 & 180 & 89 & 156 & 147 \\
\hline 25 & 86 & 61 & 40 & 77 & 166 & 104 & 6 & 129 & 57 & 237 & 177 & 181 & 58 & 113 & 148 \\
\hline 26 & 16 & 54 & 355 & 78 & 92 & 87 & 50 & 130 & 38 & 89 & 221 & 182 & 49 & 120 & 15 \\
\hline 27 & 51 & 167 & 107 & 79 & 92 & 160 & 95 & $131^{*}$ & 57 & 2 & 4 & 183 & 134 & 254 & 203 \\
\hline 28 & 66 & 29 & 116 & 80 & 106 & 210 & 238 & $132^{*}$ & 129 & 122 & 211 & 184 & 53 & 129 & 21 \\
\hline
\end{tabular}


Appendix D (cont.)

\begin{tabular}{|c|c|c|c|c|c|c|c|c|c|c|c|c|c|c|c|}
\hline P205 & & & & & & & & & & & & & & & \\
\hline 29 & 41 & 285 & 181 & 81 & 49 & 257 & 252 & $133^{*}$ & 276 & 115 & 238 & 185 & 334 & 50 & 380 \\
\hline 30 & 72 & 30 & 78 & 82 & 92 & 219 & 285 & 134 & 445 & 383 & 309 & 186 & 24 & 84 & 56 \\
\hline 31 & 51 & 36 & 16 & 83 & 371 & 256 & 49 & 135 & 68 & 81 & 244 & 187 & 76 & 85 & 56 \\
\hline 32 & 16 & 49 & 5 & 84 & 87 & 57 & 248 & 136 & 53 & 89 & 78 & 188 & 76 & 57 & 36 \\
\hline 33 & 15 & 13 & 65 & 85 & 162 & 183 & 435 & 137 & 49 & 138 & 128 & 189 & 192 & 201 & 98 \\
\hline 34 & 15 & 84 & 63 & 86 & 96 & 208 & 154 & 138 & 92 & 71 & 127 & 190 & 98 & 85 & 67 \\
\hline 35 & 85 & 34 & 241 & 87 & 79 & 267 & 22 & 139 & 236 & 339 & 103 & 191 & 258 & 187 & 241 \\
\hline 36 & 59 & 384 & 116 & 88 & 96 & 175 & 134 & 140 & 116 & 216 & 259 & 192 & 165 & 251 & 189 \\
\hline 37 & 23 & 26 & 110 & 89 & 42 & 262 & 309 & 141 & 265 & 314 & 133 & 193 & 38 & 3 & 62 \\
\hline 38 & 13 & 115 & 179 & 90 & 88 & 128 & 404 & 142 & 149 & 270 & 357 & 194 & 115 & 262 & 89 \\
\hline 39 & 19 & 114 & 36 & 91 & 90 & 46 & 39 & 143 & 74 & 118 & 176 & 195 & 83 & 68 & 39 \\
\hline 40 & 108 & 203 & 7 & 92 & 97 & 196 & 172 & 144 & 332 & 306 & 384 & 196 & 56 & 21 & 17 \\
\hline 41 & 214 & 166 & 64 & 93 & 270 & 199 & 29 & 145 & 324 & 264 & 22 & 197 & 29 & 62 & 39 \\
\hline 42 & 80 & 46 & 180 & 94 & 452 & 363 & 91 & 146 & 104 & 253 & 119 & 198 & 303 & 433 & 225 \\
\hline 43 & 37 & 40 & 96 & 95 & 48 & 319 & 297 & 147 & 51 & 65 & 238 & 199 & 18 & 0 & 43 \\
\hline 44 & 84 & 28 & 106 & 96 & 338 & 423 & 188 & 148 & 58 & 131 & 98 & 200 & 29 & 56 & 37 \\
\hline 45 & 18 & 72 & 29 & 97 & 34 & 140 & 196 & 149 & 67 & 49 & 148 & 201 & 154 & 126 & 248 \\
\hline 46 & 12 & 51 & 7 & 98 & 65 & 39 & 178 & 150 & 49 & 39 & 84 & 202 & 90 & 74 & 18 \\
\hline 47 & 29 & 86 & 252 & 99 & 50 & 120 & 136 & 151 & 107 & 364 & 272 & 203 & 93 & 95 & 38 \\
\hline 48 & 37 & 184 & 179 & 100 & 112 & 25 & 122 & 152 & 38 & 17 & 31 & 204 & 94 & 118 & 36 \\
\hline 49 & 13 & 154 & 219 & 101 & 48 & 197 & 137 & 153 & 27 & 98 & 33 & 205 & 165 & 203 & 186 \\
\hline 50 & 70 & 91 & 111 & 102 & 117 & 287 & 42 & 154 & 68 & 41 & 78 & & & & \\
\hline 51 & 217 & 304 & 61 & 103 & 50 & 170 & 179 & 155 & 207 & 386 & 168 & & & & \\
\hline 52 & 72 & 167 & 107 & 104 & 68 & 123 & 370 & 156 & 202 & 227 & 177 & & & & \\
\hline
\end{tabular}

